\title{
EVOLUÇÃO GEOTECTÔNICA DAS ROCHAS METAMÓRFICAS DO EMBASAMENTO DO CRÁTON DO SÃO FRANCISCO NA BAHIA
}

\author{
J.S.F.Barbosa
}

A elaboração, por computador, do novo Mapa Geológico do Estado da Bahia ao milionésimo, permitiu que os mais importantes trabalhos geológicos realizados nos últimos quinze anos, sobre rochas metamórficas de alto grau, fossem analisados, incluindo viagens de campo para verificação, com posterior integração dos dados. Uma síntese dessas pesquisas é aqui apresentada em etapas, visando explicar a evolução dos fenômenos geológicos responsáveis pela formação dos metamorfitos de alto grau, de idade arqueana e proterozóica inferior, do embasamento do Cráton do São Francisco na Bahia.

A - Formação de uma crosta continental precoce, gerada por processos geológicos compativeis com um modelo a dois estágios, considerados responsáveis pela geração das associações de TTGs (Martin, 1987; Martin et al., 1991). Os testemunhos desse dinamismo plutônico, encontrados tanto no embasamento interno do Greenstone Belt Contendas - Mirante (SW da Bahia) quanto em áreas restritas do Bloco do Gavião (SW da Bahia), foram datados em cerca de 3.4 e $3.2 \mathrm{Ga}$ (Martin et al., 1991; Marinho, 1991), tendo os TTGs penetrado um substrato ainda não claramente identificado.

B - Instalação de uma bacia intracratônica tipo rifte, que deu início à formação do Greenstone Belt Contendas-Mirante, cujos primeiros registros são encontrados em magmatismo vulcânico continental toleítico, cuja extrusão se realizou em 3.3/3.0 Ga (Marinho, 1991; Marinho et al., 1992). Recentemente identificou-se próximos a estes toleitos lavas komatíticas com textura spinifex, intercaladas com sedimentos químicos exalativos, sugerindo uma oceanização precoce deste Greenstone (J.C.Cunha, com. verbal). $\mathbf{O}$ estágio de expansão e de oceanização separou o Bloco do Gavião, a oeste, do Bloco de Jequié, a leste.

C - Formação de supracrustais, localizadas no Bloco de Jequié, com componente básico classificado como gabro/basalto de fundo oceânico (idade máxima de $3.2 \mathrm{Ga}$ ), além dos remanescentes de seqüências sedimentares (Boquira, Licinio de Almeida), vulcano-sedimentares (Brumado, Riacho de Santana) e Greenstone Belts [Ex: Umburanas, com lavas komatiíticas/ textura spinifex e com zircão de $3,1 \mathrm{Ga}$, encontrado em granito intrusivo na seqüência (Cunha \& Fróes, 1994)] do Bloco do Gavião, podem ter tido origem a partir de bacias intracratônicas e oceânicas, provavelmente com aberturas e fechamentos recorrentes entre as idades de 3.3 e 2.9 $\mathrm{Ga}$. Estas bacias possuiam assoalhos toléticos que subductadas, podem ter produzido plútons tonalíticos-granodioríticos que intrudiram as litologias pré-existentes. 0 Greenstone Belt de Mundo Novo, constituído de basaltos, andesitos, dacitos com textura variolítica, rochas piroclásticas, grauvacas, cherts e formações ferriferas (Mascarenhas \& Silva, 1994), situado sobre o Bloco de Mairi, é uma sequência semelhante àquelas do Bloco do Gavião referidas antes. D - Constituição de uma crosta tonalítica-granodiorítica e migmatítica, com idades a partir de

Curso de Pós-Graduação do Programa de Pesquisa e Pós-Graduação em Geofisica, Universidade Federal da Bahia. 
2.9-2.8 Ga, ocorreu não só nos Blocos do Gavião e de Jequié, mas também nos Blocos de Mairi e de Serrinha, estes últimos situados no nordeste da Bahia.

E - Intrusões múltiplas cálcio-alcalinas, de composição enderbítica-charnockítica, se colocaram no Bloco de Jequié, a partir de 2.8/2.7 Ga (Alibert \& Barbosa, 1992). A química dessas rochas, progressivamente mais potássica em direção ao Greenstone Belt Contendas-Mirante, sugere sua geração através de um mecanismo geodinâmico ativo, interpretado em termos de subducção para oeste (Barbosa et al., 1992).

F - Edificação de um arco magmático ou uma margem continental ativa no denominado Cinturão Granulítico de Itabuna (S e SE da Bahia)(Figueiredo, 1989; Barbosa, 1990; Figueiredo \& Barbosa, 1993), com produção de diversas gerações de rochas gabróicas/basálticas toleíticas e tonalíticas/dacíticas cálcio-alcalinas baixo $\mathrm{K}$. Estas últimas, sempre associadas com faixas estreitas de supracrustais, tiveram origem a partir de 2.6/2.5 Ga (Barbosa, 1990). Nessa época, no Greenstone Belt Contendas-Mirante, uma subducção para leste, sob a borda oeste do Bloco de Jequié, é proposta para explicar a existência de um vulcanismo cálcio-alcalino baixo $\mathrm{K}$, datado de $2.5 \mathrm{Ga}$. Este vulcanismo está associado com uma sedimentação detrítica das Formações Rio Gavião e Mirante que, localmente, foram intrudidas por granitos também com idades próximas a $2.5 \mathrm{Ga}$ (Marinho, 1991). Datações mais novas que estas são registradas ainda neste Cinturão: 2.4 $\mathrm{Ga}$, em monzonitos/monzodioritos de filiação shoshonítica/alcalina (Barbosa, 1990; Ledru et al., 1994) e 2.2/2.1 Ga, em tonalitos cálcio-alcalinos através isócronas $\mathrm{Pb} / \mathrm{Pb}$ (Figueiredo \& Barbosa, 1993).

G - Geração de tonalitos cálcio-alcalinos granulitizados (Complexo Caraiba), com idades U/Pb em zircão de 2.1 Ga (Sabaté et al., 1994), no Cinturão Granulítico Salvador-Curaçá (NE da Bahia), indicando que essas rochas de alto grau metamórfico são um pouco mais recentes que as do S e SE, referidas antes. No início da formação deste Cinturão, se admite o aparecimento de uma protocrosta oceânica entre o Bloco de Mairi $(2.9 / 2.8 \mathrm{Ga})$ e o Bloco de Serrinha $(2.9 \mathrm{Ga})$, sendo os tonalitos ali encontrados formados por fusão de lâminas de protocrosta oceânica (Complexo São José do Jacuípe) que se superpuseram quando da reaproximação dos dois blocos graníticos/migmatíticos, Mairi e Serrinha e, em cujas bordas, se formaram prismas acrescionais vulcano-sedimentares (Complexo Ipirá) (Melo \& Padilha, 1991).

H - Surgimento sobre o Greenstone Belt de Mundo Novo de uma bacia tipo rifte, situada em um contexto de margem continental ativa, com alta taxa de subsidência (Mascarenhas et al., 1992), possibilitando a deposição dos metassedimentos silissiclásticos do Grupo Jacobina (Formações Serra do Córrego, Rio do Ouro, etc.). Ali foram encontrados zircões com idades de $2.1 \mathrm{Ga}$, indicando uma contemporaneidade entre estes metassedimentos e as areias e arcósios da Formação Areião (topo da sedimentação do Greenstone Belt Contendas-Mirante), datados em torno de 2,2/2.1 Ga (Marinho et al., 1992).

I - Formação do Greenstone Belt do Rio Itapicuru, sobre o Bloco de Serrinha. Neste Greenstone, idades de $2.2 \mathrm{Ga}$, encontradas em "pillow" lavas, e de $2.1 \mathrm{Ga}$, identificadas em vulcânicas félsicas, registram a presença de uma bacia extensional do tipo "back-arc" (Silva, 1991).

J - Tectônica tangencial de rampas frontais com componentes transcorrentes, que teve início pelo menos em 2,4 Ga (Ledru et al., 1994), sugere, no S e SE da Bahia, a obducção do arco magmático do Cinturão Granulítico Itabuna sobre o Bloco de Jequié e deste sobre o Greenstone Belt Contendas-Mirante. Dobras deitadas com vergência para oeste e, às vezes redobradas coaxialmente, exibindo formas isoclinais, são encontradas nesses terrenos metamórficos de alto grau, atestando o estilo dessas deformações dúcteis.

K - Aproximação do Bloco de Serrinha em relação ao Bloco de Mairi, no NE da Bahia, representando uma tectônica colisional que atingiu as rochas tonalíticas de $2.1 \mathrm{Ga}$ do Complexo Caraiba. Completada a colisão, em ambos os blocos, e no interior do Cinturão Granulítico Salvador-Curaçá, as foliações das rochas passaram a mostrar vergências centrípetas, voltadas em 
direção aos protocontinentes (Melo \& Padilha, 1991). Na parte norte deste Cinturão, por exemplo, são notadas dobras deitadas e "thrusts" de baixo ângulo, com vergência para leste, que colocam supracrustais (Complexo Ipirá) e lâminas do substrato oceânico (Complexo São José do Jacuípe) sobre as rochas do Bloco de Mairi e sobre o Greenstone Belt de Mundo Novo. Fatias de rochas ultramáficas intercaladas em quartzitos do Grupo Jacobina são consideradas como resultantes deste embricamento tectônico (Sabaté, 1992).

L - Espessamento crustal a $S$ e SE da Bahia, com a produção de um metamorfismo regional de média $\mathrm{P}(7 \mathrm{kbar})$ e alta $\mathrm{T}\left(850^{\circ} \mathrm{C}\right)$ e com seu pico estimado em torno de $2.0 \mathrm{Ga}$ (Barbosa, 1990; Ledru et al., 1994). Nesta etapa se estabeleceram novos ambientes crustais nas fácies granulito, anfibolito e xisto-verde. Rampas tectônicas com empurrões de leste para oeste seccionaram as isógradas do metamorfismo, possibilitando a colocação de mega-blocos de rochas granulíticas, parcialmente retrometamorfizadas para a fácies anfibolito, sobre rochas das fácies granulito, anfibolito e xisto verde. Esta feição, onde terrenos de mais alto grau se posicionam sobre aqueles de mais baixo grau, se verifica não só nas partes $\mathrm{S}$ e SE, mas também na parte NE do Estado, no Cinturão Salvador-Curaçá, que também teve o seu pico metamórfico granulítico próximo de 2.0 $\mathrm{Ga}$ (Sabaté et al., 1994).

M - Intrusão de granitos crustais, sin e tardi-tectônicos, atravessando os segmentos de rochas empilhados pela tectônica. Com maior concentração no NE e SW da Bahia, em geral exibem idades em torno de $2,0 / 1.9 \mathrm{Ga}$, e são admitidos como tendo origem a partir da fusão de rochas hidratadas da fácies anfibolito, colocadas tectonicamente sob rochas da fácies granulito. Também em torno destas idades verificou-se a intrusão de corpos máficos-ultramáficos, tanto a SE como a $\mathrm{NE}$, pouco ou nada deformados, indicando o final desta tectônica principal que atingiu as rochas de alto grau do embasamento do Cráton.

$\mathrm{N}$ - Deformações tardias transcorrentes com evolução retrometamórfica se efetivaram tanto a $\mathrm{S}$ e $\mathrm{SE}$ como a NE. Atribui-se a estes cisalhamentos o alojamento de corpos de sienitos, em geral com idades mínimas de $1.9 \mathrm{Ga}$, cortando granulitos mas, intrusivos em ambiente crustal da fácies anfibolito.

\section{Referências Bibliográficas}

ALIBERT, C.; BARBOSA, J.S.F. (1992) Ages U-Pb determines a la "SHRIMP" sur des zircons du complexe de Jequie, Craton de São Francisco, Bahia, Brésil. In: REUNION DES SCIENCES DE LA TERRE, 14., Toulouse, SGF, 1992. p.4.

BARBOSA, J.S.F. (1990) The granulites of the Jequie complex and Atlantic coast mobile belt, southern Bahia, Brazil; an expression of Archean/earty proterozoic plate convergence. In: VIELZEUF, D.; VIDAL, P. (Eds.) Granulites and Crustal Evolution. Dordrechet, Kluwer Academic. p.195-221. (NATO ASI series. Serie C, v.311)

BARBOSA, J.S.F.; MARINHO, M.M.; SABATÉ, P. (1992) Petrologic and Geochronologic Evolution of the Oldest Segments of the S. Francisco Craton, Brazil. IGCP Project, 7-28, 75p.

CUNHA, J.C.; FRÓES, R.J.B. (1994) Komatiitos com textura spinifex do Greenstone belt de Umburanas, Bahia. Série Arquivos Abertos, n.7, p.1-29.

FIGUEIREDO, M.C.H. (1989) Geochemical evolution of eastern Bahia, Brazil; a probable early proterozoic subduction-related magmatic arc. Journal of South America Earth Sciences, v.2, n.2, p.131-145.

FIGUEIREDO, M.C.H.; BARBOSA, J.S.F. (1993) Terrenos metamórficos de alto grau do Cráton do São Francisco. In: SIMPÓSIO SOBRE O CRÁTON DO SÃO FRANCISCO, 2., Salvador, SBG, SGM, CNPq. p.63-84. 
LEDRU, P.; COCHERIE, A.; BARBOSA, J.S.F.; JOHAN, V.; ONSTOT, T. (1994) Ages du metamorphism graulitique dans le Craton du São Francisco (Brésil): implications sur la nature de l'orogene tranzamazonien. Comptes Rendus Academie de Sciences Paris. Serie II, t.318, p.251-257.

MARINHO, M.M. (1991) La sequence volcano-sedimentaire de Contendas-Mirante et la bordure occidentale du Bloc de Jequié (Craton do São Francisco), Brésil: un exemple de transition archeen-proterozoic. Clermont-Ferrand II, 345p. (Tese - Doutorado) Universite Blaise Pascal.

MARINHO, M.M.; SABATÉ, P.; BARBOSA, J.S.F. (1992) Petrologic and Geochronologic Evolution of the Oldest Segments of the S. Francisco Craton, Brazil. IGCP Project, 29$55,75 \mathrm{p}$.

MARTIN, H. (1987) Archaean and modern granitoids as indicators of changes in geodynamic processes. Revista Brasileira de Geociências, v.17, n.4, p.360-365.

MARTIN, H.; SABATÉ, P.; PEUCAT, J.J.; CUNHA, J.C. (1991) Un segment de crôte continentale d'age archeen ancien (3,4 milliards d'années): le massif de 7 Voltas (Bahia, Brésil). Comptes Rendus Academie de Sciences Paris, Serie II, t.313, n.5, p.531-538.

MASCARENHAS, J.F.; CONCEIÇÃO FILHO, V.M.; GRIFFON, J.C. (1992) Contribuição à geologia do Grupo Jacobina na região Jacobina, Pindabaçu. In: CONGRESSO BRASILEIRO DE GEOLOGIA, 37., São Paulo, 1992. Boletim de Resumos ExpandidosSessões Temáticas. São Paulo, SBG, v.2, p.141-142.

MASCARENHAS, J.F.; SILVA, E.F.A. (1994) Greenstone belt de mundo novo: caracterização e implicações metalogenéticas e geotectônicas no Cráton do São Francisco. Série Arquivos Abertos, n.5, p.1-31.

MELO, R.C.M.; PADILHA, A.V. (1991) Programa levantamentos geológicos básicos do Brasil. Folha Pintadas. SC. 24-Y-D-V. Escala 1:100.000. Brasilia, DNPM/CPRM.

SABATÉ, P.; PEUCAT, J.J.; MELO, R.C.; PEREIRA, L.H.M. (1994) Datação por Pb evaporação de monozircão em ortognaisse do complexo Caraiba: expressão do crescimento crustal transamazônico do cinturão Salvador-Curuçá (Cráton do São Francisco, Bahia, Brasil). In: CONGRESSO BRASILEIRO DE GEOLOGIA, 38., Camboriú, 1994. Boletim de Resumos Expandidos-Simpósios. Camboriú, SBG. v.1, p.19-220.

SILVA, M.G. (1991) Evidências de uma tectônica de colisão-subducção no Proterozóico Inferior no nordeste do estado da Bahia. In: SIMPÓSIO DE GEOLOGIA DO NORDESTE, 14., Recife, 1991. Atas. Recife, SBG-NE. p.216-219. (Boletim, 12) 